\title{
The Spectacle of Difference: Dance and Disability on Screen
}

\author{
Sarah Whatley
}

$\mathrm{T}$

he way in which disabled dancers appear in performance and are represented through performance has been the subject of discussion for a number of writers in recent years. 'These writings have drawn attention to how disabled performers challenge dominant views of disability as variously standing for less than, as other, as diminished, and as equated with loss. These writings, though relatively few in number, have been important for those working within the professional dance community. They have also stimulated further thought about how audiences view and form judgments about disability in performance and how disability presents useful challenges to the prevailing dance aesthetic. But, much of the existing writing is confined to addressing and critiquing the live performance event, whereas the focus for this essay is dance and disability on screen, which might raise different questions about how the viewer encounters and experiences disability, about the communion between viewer and screen and which also gives rise to a spectacular event: the spectacle of difference.

I am aware that looking at disabled dancers on film might usefully draw on different registers for sense- and meaning-making. As Sandahl and Auslander point out, disability is something one does rather than something one is (10). ${ }^{2}$ For people with disabilities, their experience of being 'out of the ordinary' and 'out of place' means that disability is already a kind of performance for them. By looking towards a broader theoretical framework, I want to explore what impact the framing of the screen has on the identities of those who dance with disabilities, how disabled dancers perform their own identities, and how this is read and interpreted by the viewer. So, my focus is on the screening of disabled dancers within dance films and how readings of disability on screen might generate a theory of looking; might disrupt a presumption of the relationship between screendance and mobility; and therefore make clear the political implications of screendance. In each of the screendance examples I refer to, the body itself is therefore fundamental to my reading and response.

Disability theorists Mitchell and Snyder discuss how the relationship between screen and viewer calls on particular notions of spectatorship. ${ }^{3}$ They interrogate the nexus between spectator and the filmed disabled body as a spectacle by delving into "the psychic structures that give meaning to disability as a constructed social space" (157). I acknowledge that I am not a neutral spectator. By writing from my own embodied, subjective position I accept that I am not writing as a viewer with a disability, ${ }^{4}$ and whilst I do not wish to ignore the viewpoint of audience members with disabilities, it is not the main purpose of this essay to explore what might be seen as a disabled gaze in relation to film. Nonetheless, I wish to distance this study from those projects that might treat disabled bodies as research objects of investigations: a position where "bodies marked as anomalous are offered for consumption as objects of necessary scrutiny-event downright prurient curiosity" (Mitchell and Snyder 157) and which place disabled people under a scientific gaze. 
I raise these points because my intention is to bring attention to how disabled performers contribute to visual literacy in relation to screendance and disrupt viewing strategies, thereby challenging the assumed mastery and domination of nondisabled performers. On one hand, viewers might experience the film as a medium that places distance between them and the disabled performer. In this case, bodily difference is experienced as "exotic spectacle" (Mitchell and Snyder 157). Viewing a film is not like attending a live performance in which the audience is at least in the same physical space as the performer, however remote and distant, and where there is the potential for a 'tactile' communion based on exchange between performer and audience. And yet, the viewer can be drawn into the film for a variety of reasons; film-spectator relations are always complex. Looking at disabled dancers on screen might well seduce the viewer into experiencing a range of bodily sensations that generate new kinds of appreciation.

If so, is this due to the medium itself (the film)? Or the subject matter? What is it that determines a particular mode of viewer engagement?

In an earlier paper, I postulated a range of viewing strategies that emerge from what I termed a presumption of difference when audiences view disabled dance performers. ${ }^{5}$ I argued that the viewer attends to dance that is performed by disabled performers differently; their critical framework is not the same as that which might be applied to a performance by non-disabled dancers. I am now reconsidering that theory in relation to this current project. Although the research that led to those categories was conducted directly with disabled dancers who gave voice to their own experiences, by proposing a categorization of viewing strategies, ${ }^{6}$ I assumed a privileged and non-disabled position for the viewer. I thus inadvertently positioned the disabled performer as other. Whether or not these strategies might be straightforwardly applied to screendance, screen theorist Richard Rushton offers what might appear to be a similar proposition, drawing on Deleuze's theory of spectatorship (1986) to consider the bodily mode of audience engagement with film (2009). ${ }^{7}$ Rushton observes that Deleuze "has no explicit conception of the cinema spectator," (47) and yet, he contends that a theory is implicit in Deleuze's Cinema books (1986, 1989). ${ }^{8}$ Rushton claims that Deleuze's spectator is created by the film and does not pre-exist it; there is no prior 'subject' before comprehending the film. The spectator is fused with the film. There is no spectator who watches/listens; subjects (subjectivities) are formed by the cinema, by the act of experiencing the film. Rushton builds on Deleuze's theory by suggesting that there is an important distinction in the spectator's relationship to any film, which he defines as a process of either absorption or immersion (48-49). Rushton then looks to art historian Michael Fried to propose that the mode of absorption is one in which the spectator is drawn into the film; s/he senses that $s /$ he is there in the film whilst acknowledging that s/he cannot be there. However, in the mode of immersion, the film comes out to the spectator so as to surround and envelop, to enter the viewer's own body (Rushton 51). Each of these modes provides the viewer with a different (bodily) engagement with the film.

Rushton's views, though not applied to any particular film genre, challenge the notion of there being two separate forces at play in watching dance on film: the film and the viewer. If they effectively meld together through the viewing-becoming a singular experience with neither existing independently of the other-then a taxonomy of viewing strategies, which exists prior to and independent of the viewer and the work, cannot be possible. It 
is in this respect that the series of viewing strategies I set out in relation to disabled dance in performance diverges from that proposed by Rushton. Nonetheless, I view these same viewing strategies as a provocation intended to call attention to the potentially destructive and unhelpful ways in which disabled performers are categorized, in order to prompt thought about spectator/performance relationships, which then can influence interactions beyond dance in wider society.

It may be that, in the case of screendance featuring disabled performers, the viewer is neither absorbed nor immersed in quite the way described by Rushton. Rather than the spectator being taken into the film or the film taking over the viewer, the spectator 'meets' the film in a complex space that allows for a shared somatic, kinaesthetic, intercorporeal, intersubjective, and visceral involvement, which invites the viewer to identify with the dancing human subject/s. But, depending on the bodily mode of engagement of the viewer, this identification might reinforce a notion of human difference, thereby allowing the viewer to "witness spectacles of bodily difference without fear of recrimination by the object of this gaze" (Mitchell and Snyder 157). Dancers with disabilities therefore have good reason to feel anxious about how their work is seen and evaluated in its own terms, prompting them to foreground their own experience of disability and their marginalization within an art form that has traditionally fixed the gaze on the sleek, perfect, flawless dancing body and which too often conforms to conventional notions of beauty. Often very aware of the politics of representation and their own agency (or lack of) in how they are portrayed and interpreted in performance, dancers with disabilities frequently contribute to the discourse of 'difference,' performing their own identity, making work about their own experience of disability. Disability becomes subject matter as well as material content.

There are relatively few dance films, readily available, that feature disabled dance artists. It may be that whilst there are many disabled dancers, they tend not to be regarded as professional artists unless they are members of the few established companies described as either disabled or 'integrated' - those where disabled and nondisabled dancers perform together. ${ }^{9}$ The filmed records of these companies show the scale of the incursion of disabled dancers into the mainstream (Smith 81). But labeling the company's work as 'integrated' poses another potential dichotomy. Already, the dance and therefore the experience of the audience are likely colored by an expectation of bringing together two different components or categories of 'normal' and 'other.' When applied to disabled people this can, according to Campbell,"suggest their categorization as sub-human, giving definition to their non disabled 'counterparts' $(27) .{ }^{10}$

Similarly, using the definition of 'screendance' offered by South East Dance as "dance made specifically for the camera, for presentation as a single screen film or video," it is worth noting that there are very few disabled dance and screendance makers: ${ }^{11}$ disabled dancers tend to be performers but less often choreographers or dance directors. ${ }^{12}$ Disability tends to be in front of the camera rather than behind the camera unless, as in the case of Laura Jones's Re: Bound (2008), she is in both roles. ${ }^{13}$ In Jones's film, disability is performative; her disability is both subject and subject matter. Jones self-directs a short self-portrait-in-film of her experience as a dancer who uses a wheelchair. Her close study of her relationship to space and time is sensitively worked into an intimate film. The camera plays with varying perspectives: sometimes filming from above, from below, and from all sides; sometimes with the dancer in full frame; and often close to the moving body, focusing on skin, muscle, 
breath, and the play between the textures of the dancer in her chair, which is set against the textured walls and floor of the studio setting. With a soundtrack of unaccompanied piano, the film is an exploration of a body that finds articulation within physical limitationsJones has full mobility in her arms and upper body but her legs are immobile-expressed clearly in the formulation of the title Re:Bound. These limitations are emphasized in the compositional journey she makes, beginning with small, detailed, rippling hand and arm movements through to spinning herself around in her chair. The camera follows her increasing speed, capturing only fragments of the dancer and her chair, blurred and indistinct, until she comes to almost stillness, performing 'near-exhaustion,'to remind the viewer that manipulating her wheelchair is hard work and requires stamina. She regains her breath and begins again. This cyclical structure tells us something of her efforts, her sense of her own corporeality, and her desire to find a medium; in this case film, which will allow her to find an expression to break through her physical boundaries.

To briefly return to Mitchell and Snyder's observation about the "exotic spectacle," distance between the disabled performer and non-disabled viewer may generate a different kind of viewing experience, determined by the viewer's perception of how far the disabled dancer appears to bridge the distance or overcomes disability in performance (157). By contrast, when a performer has become disabled through accident or illness, the experience of disability is often played out in the dancer's own performance. In Re:Bound, intimacy with the dancer through close camera work might reduce the distance between performer and spectator, but Jones seems to perform a 'longing' in her dance, implying a distance between her physical reality and that which she desires to be. The grace and fluidity of her upper body juxtaposes the immobility of her lower body. And yet the film's close attention on Jones' wheelchair as extension of her body, as much as tool to facilitate movement, softens the binary between ability and disability, diverting thought away from what might have been, or once was.

Some of the film records of professional disabled/integrated companies appear on YouTube and are documentary in style or serve as promotional material-some include short excerpts of works interspersed with commentary and touring information. The discourse of these documentary films seems intent on stimulating an emotional response. Frequent use of terms such as "tragic," "affliction," "confined," and "courageous" give shape to the commentary or text-line. Many portray the disabled body as filmic spectacle, focusing on gymnastic display despite disability, or on the dancer's ability to overcome the limitations of disability. Many of the comments posted by viewers confirm the spectatorial pleasure derived from these viewings.

More compelling are those videos that include the voices of those who dance. Catherine Long, a disabled dancer in the US-based Gimp project (which as a title deliberately foregrounds the offensive language that disabled people have to contend with) performs in Collision and talks about how performing enables her to take control. ${ }^{14}$ Whereas in the street, people will look at her, an event that she cannot control, in the theatre she is intentionally directing the viewer to look at her-something that is clearly empowering for her. This privileging of the disabled dancer's voice not only draws deliberate attention to the politics of disability but also explicitly foregrounds a cultural perspective informed by and within the phenomenology of bodily difference. Referring to phenomenology in this context draws attention not only to the capture of disability perspectives on film but also 
to the meaningful influence of disability upon one's own subjectivity and upon cinematic technique itself (Mitchell and Snyder 170).

The status of the disabled performer/choreographer means that there is perhaps little distinction between the disabled artist's experience of the live and the screen. When disabled dancers are involved, the distinction that Kappenberg makes between "body as tool" and "body as site" in screendance, is blurred if not removed altogether (96). ${ }^{15}$ The body is unavoidably a tool for inscribing a particular (and individual) experience of embodiment whilst also a site for the exploration of limitations and possibilities in a generic sense. Thus the individual body inadvertently stands for a collective body; a body as site for contemplation of a universally coded condition of disability. And yet the film of Catherine Long, as well as the film choices made by Laura Jones, brings attention back to the individual artist because of their control of how they are represented on film and in performance. Each dancer finds ways to control the viewer's gaze in order to speak beyond the visual text of her disability. Long uses the film medium to reinforce the control she experiences when performing in a live setting whereas Jones takes control through her editing choices. By controlling the filmic apparatus and the medium of their representation, they direct and perform their own individual bodily reality.

Other screendance films provide different representations of disability or represent the disabled performer differently because s/he is not in control of the film process in the same way; control lies with another. David Toole, a disabled, British, dance artist performs in The Cost of Living (2004) ${ }^{16}$ conceived and directed by Lloyd Newson, based on his earlier stage production. ${ }^{17}$ The film runs for thirty-five minutes and tells a story of two men who are street performers in an end-of-season English seaside resort. The locations are various and shift between urban, rural, domestic, and public sites. The narrative develops around the men's relationship, their encounters with others, their attempts to attract women, their vulnerabilities and insecurities, as well as their tactics for survival.

The film introduces several characters that display idiosyncratic behaviors, drawing attention to the way in which society's prejudices too easily position people as deviant or as outcasts. In this context, disability might be read as simply one more deviance. Dialogue traces the dynamics between the two central characters: Eddie and David. These are their real names; Eddie Kay and David Toole. Eddie has a tough, aggressive. and confrontational demeanor. He is not afraid to speak his mind. David speaks more through his movement and how he moves - or more specifically, how he either moves himself (propelled, supported, and animated through this arms) or is moved by others (carried, supported, lifted, or steered when in his wheelchair). David has no legs; his body ends at his torso/hips. ${ }^{18}$ Toole's physicality is very much a reality; there is no film trickery, implying that through the film, he performs his own narrative, his own authentic autobiography. The film as narrative thus blurs the boundary between fiction and reality, supported by the play between and juxtaposition of "real" and constructed locations. Although Toole is the only performer with an overt physical disability in the film, his extreme physicality and difference is less pronounced within a film that is concerned with excess and extremes of behavior amongst the other characters. The power of the film is located in bodies and bodily sensation that might be characterized as excessive (Mitchell and Snyder 139).

Paradoxically, several filmic and/or staging devices also effectively erase or diminish the reality of Toole's disability (he often appears behind open windows, seen only "from the 
waist upwards"). Then, when he comes into full view, the other players exhibit a matterof-fact attitude. The viewer is encouraged to see David's disability as just another bodily possibility. But at all times, he controls his own mobility, whether he moves independently or is lifted, carried, or pushed in his wheelchair by others in a functional, practical way. In a wheelchair, David is no longer a body without legs but a body seated, differently mobile but now subject to the many presumptions and preconceptions afforded to all those categorized as 'wheelchair users.'19

Despite the radical approach to "normalizing" disability within the context of the narrative, the radical and even shocking nature of David's disability points to the central motif and theme of the film. In one scene, David's own subjectivity is foreground. David is "sitting" on the bar, apparently "chatting up" the viewer or an imagined, invisible, other. We witness him confronting our own embarrassment and discomfort: "would you like to dance? Don't be embarrassed ... all of me or maybe just my arms ... can't be my legs ... I bet you're wondering what it's like... Well, I'll tell you ... It's small but it's peachy ... I saw you looking ... so would you like to dance? I'll be looking for you." In exposing the questions we might not dare to ask, he refuses to be emasculated by his disability, challenging how we might categorize him as asexual, freak, spectacle. In the same way that Catherine Long tells us on camera about her sense of being empowered when on stage, this reversal of power is turned into theatrical device as David takes control. Any discomfort he may experience at being looked at is turned back on the viewer who is made more uncomfortable by his direct questioning. Moreover, in this more intimate encounter, he confronts his own sexuality and dares the viewer to regard him as sex object.

The same device returns in a later scene, but this time the viewer is "twice removed"; the single lens of the camera is replaced by a double lens. This time the questions are not directed toward the viewer. David is subjected to an aggressive form of questioning by the cameraman, who with hand-held camera overshadows David, intrusively filming close-ups, and asking uncomfortable, personal questions. David is surrounded, pursued, interrogated, and seen close-up through the lens of the camera. He asks without wanting a reply "what happened to your legs, I want to know ... Have you ever been in a fight? If you hit me first it's OK if I hit you back isn't it because you're a man? Do you trust me? ... Because I don't trust you." As witness, the viewer is made uncomfortable, unable to intervene, and reminded of society's participation in the treatment of disabled people; how disabled people are stripped of their control, their dignity, their identity. And yet David is quickly back in control, heroic, undeterred by his encounter, leading the group into a fast moving, ensemble, group dance. Advancing like a military force, the dancers move together in a show of strength and solidarity, as a metaphor for the battleground that typifies David's day-to-day experience as a disabled man.

One scene within the work is posted on YouTube and has attracted many viewings and comments (one even asking if David's disability is camera trickery). The scene begins with the camera at ground level, filming close-up on ballet dancers'feet and legs within a dance studio setting as they move through barre exercises. It cuts to Eddie and David who look in from outside, seemingly unnoticed by the female dancers. ${ }^{20}$ David then enters the studio, unacknowledged, until he meets one dancer and they move together through a fluid duet. They begin a duet, in full camera frame, built around close contact and exchanges of weight, counterpull, counter balances, and seamless lifts. 
Conventional in form, the pas de deux upholds traditional dance values in its structure: combining strength, control, athleticism, and smooth, effortless performance. This spectacle of dancerly inventiveness (particularly due to David's very different physicality) is confused by the lack of attention given to the duet by the other dancers in the space. Do they choose to ignore the dance because it is unimaginable, distasteful — or is it, after all, just ordinary? Or is the duet actually a fiction, a fantasy shared by the two dancers? Ferris points out that "disability obscures the blurry lines that separate fiction and art from real life. Is disability 'fictional', or is it 'real'?" (56). ${ }^{21}$ In many ways, The Cost of Living continually blurs the line between fiction and reality and none more so than here, with the framing of the duet within a setting (the ballet class) that traditionally prepares the dancer for the fictionalized world of the theatrical performance event. So Newson's ironic divertissement plays on the conventions of the ballet.22 The duet challenges the dominant aesthetic of dance by appropriating the classical form and the duet device. By deliberately foregrounding and bringing together two extremes, two excesses, embodied by the classical ballet body and the disabled body, Newson forces the viewer to confront perfection and imperfection, those who cannot pretend and those who do not fit in.

The duet also takes time out from the narrative to further play with presumptions of what David can and cannot do. By positioning it within a context of "not noticing," the invasive gaze of the viewer, which marked the previous scenes, is neutralized. And yet, the camera gets close-up, offering the viewer a "private dance," an intimate encounter with disability to permit a form of communion with the dancers. The viewer is permitted to get close to a disabled body, a body more often concealed from public view, without fear of recrimination for looking, for staring. Mitchell and Snyder propose that this exacts a double marginality: "disability extracts one from participation while also turning that palpable absence into the terms of one's exoticism" (158; italics in original). Looking back to Catherine Long's comment, the theatre is a space where she feels empowered by having some control over the audience gaze. By placing her dancing alongside her comments on film, the viewer is both able to exercise curiosity by viewing bodily difference whilst at the same time hearing how she exercised her own agency within the performance.

The duet operates in different ways. Set within the context of the whole film, the duet provides a brief escape from the harsher reality of life beyond the relative safety of the studio. David's disability is not masked, neither is it compromised or exploited. It is not that he overcomes his disability, but rather he is allowed to challenge his own capability, demonstrating how he can dance on equal terms with his partner; much of the movement material seems to be sourced from his own body. Unlike disabled people who are made child-like in their frequent dependence on others, David asserts his autonomy through playing an equal part in the duet. Although David might be seen to be negotiating a selfimage with respect to a normative formula, in this case the well-established formula of the male/female duet, his dance leaves a "permanent mark upon 'normative' modes of embodiment" by shifting thought about what a male/female duet should be; because it is on film, as a "permanent record" and widely viewed (on YouTube), the duet becomes emblematic of what disability can stand for in dance (Mitchell and Snyder 169).

Campbell observes that at first, the scene "evokes pity for Toole, who seems too long to join the able bodied dancers, before surprising the viewer with the grace of his subsequent deeds" (28). But in her critique of this scene, she does point out that it can promote 
a patronizing image in which David is "watched as a heroic disabled dancer" (Campbell 28). She adds that such portrayals are unhelpful, "seeing the dancer is replaced by seeing the disability, and means that it lessens the importance of his artistic contribution deeds" (28). In the context of the film as a whole, David may well be viewed as heroic, but perhaps Newson invites this reading, forcing the viewer to confront the reality of the disabled hero by leaving David alone again at the end of the duet before he departs, unseen again by those around him.

The Cost of Living is rich with imagery, and although Toole is the only disabled performer in the film, it avoids a tokenistic approach to disability. We are left with many images of how David confronts, subverts, exploits, and overcomes his disability, both to further the narrative and to challenge the conventions of dance. Ultimately, Toole's agency within the film is somewhat ambiguous precisely because it blurs the line between fiction and reality. His motivation to perform may be motivated more by his desire to be recognized as fully human, to remedy the lack which he embodies, as a desire to take control of his own representation on film.

A quite different exploration of dance and disability is explored in StopGap's short dance film Chris \& Lucy (2008). ${ }^{23}$ Unlike The Cost of Living, the choreography is credited separately from the film direction, implying a separation between those who made the dance and those who are behind the camera and made the film. This two-stage collaborative process implies a fracturing between the "screen" and the "dance." But Chris and Lucy are again the names of the two performers in the film (Lucy Bennett and Chris Pavia), once more collapsing the distinction between the role and performer, and reflecting a wider trend in dance in the last decade towards personal narratives as subject matter. As before, the dancers might be seen to be performing their own individual stories. Another link is the seaside location, but there is no extended narrative structure. Whilst the work is clearly site-based, it does not attempt to develop a more developed relationship with or response to the site. Chris \& Lucy is a duet for a learning disabled man (Chris has Down's syndrome) and a nondisabled woman, and therefore might be seen to be "a creative collaboration that permits the full expression of individual subjectivity and experience for all involved" (Perring 177). ${ }^{24}$

The film begins with the dancers meeting and walking together to the beach with natural sounds as a backdrop. They appear to be alone. We see them facing out to sea with their backs to the camera. As they begin to dance, the camera moves around them, close up to their dancing, participating in their tactile exchange before moving further away, now looking from the outside in. As in the male/female duet in The Cost of Living, the duet follows a conventional dance duet format although it extends for a considerably longer period of time (approximately nine minutes). The two dancers move through a sequence emphasizing contact, sharing of weight, lifts, balances, and gesture. Their touch is functional yet suggests a caring and careful relationship. Chris tends to carry Lucy more, and Lucy carries her shoes. ${ }^{25}$ Each dancer has a short section in which they dance alone, momentarily isolated and separated — but the other is close by. There are brief moments of humor, but it begins and ends in a more melancholy mood. The close proximity of the two dancers focuses attention on the importance of the tactile sense in motivating movement; however, on screen the physical exchange between mover and watcher is absent. Moreover, the camera tends towards framing the dance as a theatrical event, reproducing 
the distance created between performers and viewers in a live, staged performance and detracts from what might have been an intensive communion between viewer and film if the camera stayed closer to the dancers' bodies. However, despite the public setting of a beach, the camera appears to be the only witness to their dance. Though simply constructed, the dancers seem to be liberated in this "natural" environment, away from the fear of the judgment of onlookers.

The separation from the reality of human relationships and encounters in Chris \& Lucy is a sharp contrast to the social world created in The Cost of Living. The simplicity and "naturalness" implied by the duet might be seen to play down the exoticism of this pairing between a learning disabled man and nondisabled woman. The freedom they find in their dance together suggests friendship, mutual support, and shared responsibility. But, because of the emphasis on equality as theme and Chris's apparent ability to overcome his disability to perform on equal terms with a nondisabled partner, difference (or more precisely its attempt to minimize difference) becomes subject matter. As an integrated performance, it tends to highlight the problem described by Campbell, who asks whether the pairing of disabled with nondisabled dancers projects an image of the disabled performer as a separate component that echoes the traditional dance partnership of female reflecting male (27). In this case, the male/female roles are reversed; Chris reflects Lucy and in doing so, the power relationship is inverted but separation and difference remain.

In looking closely at these two duets, in each case performed by a disabled male and a nondisabled female, I am interested in the extent to which these pairings disrupt normative gender ideologies. Dance as a discipline/practice is often plagued with preconceptions of the male dancer as homosexual. When the male dancer is a disabled dancer, might there be a different reading? Does disability signal that that sex is "off limits?" Manderson and Peake argue that "[s]ince masculinity is defined as able-bodied and active, the disabled man is an oxymoron" (233). ${ }^{26}$ In Chris \& Lucy, Chris is portrayed as gentle, easily supported, and led by Lucy, comfortable in his tall but soft body. Chris's masculinity and therefore gender difference are downplayed in the neutrality of their dress, in the sharing of movement material, and in the more protective and maternal role, played by Lucy. The partnership functions inter-textually in a quite different way in the duet in The Cost of Living. Newson explores issues of masculinity and femininity, partly through the narrative and partly through the way in which contradiction is embodied within the individual dancer. Toole's overt masculine physicality or "hypermasculinity" is expressed through his shaved head, and muscular upper body and arms but is abruptly contradicted by the absence of his lower body. He performs with agility and athleticism juxtaposed with softer and more extended movement. He deliberately plays with others' expectations of his own masculinity and he appears to enjoy exposing the ruse of Eddie's masculinity. He also confronts expectations of a disabled man's withdrawal from sex by deliberately raising the possibility through his speech in the film (Manderson and Peake 237). He seems to gain a newfound bodily agency and sociality in his performance of masculinity and sexuality (Manderson and Peake 237). In short, how gender is played out in the disabled body of David is important in how we read the representation of disability in the film.

My aim in this essay has been to explore how these dance films participate in the debate about difference and disability. Each work provides a different glimpse into how disabled people deal with being-in-the-world (Merleau-Ponty). ${ }^{27}$ I have variously argued 
that each accentuates or erases disability in different ways by using different filmic and choreographic devices. What is of particular interest in the context of this essay is the extent to which the medium of film participates in the representation of disability, either by providing the promise of generating interest in bodily difference as an exotic spectacle or by diminishing the distance and therefore the difference between viewer and disabled dancer (Mitchell and Snyder 157). At times, the camera brings the spectator closer to the reality of disability. Touch between dancers is captured and emphasized through the close proximity of the camera, reorienting the viewer's senses away from the visual to the tactile sense. The physical presence of the camera might be emphasized or conversely, the camera adopts a disembodied eye, as in classical cinema (Kuppers 157). ${ }^{28}$

The duets selected for detailed analysis tend to reinforce the dualisms and binaries that operate more widely within the frame of dance and disability: able/disabled, controlled/in control, passive/aggressive, and so on. A condition of "otherness" associated with disabled people tends to be emphasized by pairing disabled with nondisabled dancers. When the disability is marked as in the case of David Toole, this is probably unavoidable. And yet performance can demonstrate that disability can be beautiful, which helps to remove the automatic equation of disability with loss. As Campbell points out (with reference to Toole's performance in The Cost of Living):

Used in the appropriate context, Toole's graceful and unique style is a rejoinder that his physique permits him to dance in a way that the non-disabled can admire but not replicate: appreciation (and even envy) are likely to supersede sympathy. (29)

Importantly, the communion between viewer and performer when the dance is on film gives rise to a mode of visual consumption that finds room for different gazes. Viewers come to see disabled dancers through various filmed events and therefore different lenses. YouTube can be a powerful tool for providing viewers access to a range of video content. Mitchell and Snyder argue that a "complex space exists between images and their spectatorial reception by audience members" (158). But when viewed as a collective body of film content featuring disabled performers, and which is the principal vehicle for consumption by the viewer who comes to dance via the screen, a sense of separation or otherness is often reinforced, thus underlining a particular relationship between subject and viewer and that gives rise to a spectacle of difference.

\section{Notes}

1. See for example:

Albright, Ann Cooper. "Strategic Abilities: Negotiation the Disabled Body in Dance." Moving History/Dance Cultures: A Dance History Reader. Ed. A. Dils and A.C. Albright. Hanover, CT: Wesleyan UP, 2001. 56-66. Print.

—. Choreographing Difference: The Body and Identity in Contemporary Dance. Hanover, CT: Wesleyan UP, 1997. Print.

Benjamin, Adam. Making an Entrance: Theory and Practice for Disabled and Non-disabled Dancers. London: Routledge, 2002. Print.

Kuppers, Petra. Disability and Contemporary Performance: Bodies on Edge. London: Routledge, 2003. Print. - Sirens: Performance Technology, Community Dance and Disability Embodiment. Tallahassee, FL: Congress on Research in Dance, 2005. Print.

—. "Bodies, Hysteria, Pain: Staging the Invisible." Sandahl and Auslander, 147-62. Print.

Carrie Sandahl and Philip Auslander, eds. Bodies in Commotion: Disability and Performance. Ann Arbor: $U$ of Michigan P, 2005. Print.

Smith, Owen. "Shifting Apollo's Frame - Challenging the Body Aesthetic in Theater Dance." Sandahl and Auslander, 73-85. Print. 
Whatley, Sarah. "Dance and Disability: The Dancer, the Viewer and the Presumption of Difference." Research in Dance Education 8.1 (2007): 5-25. Print.

2. See note 1 .

3. Mitchell, David and Sharon Snyder. Cultural Locations of Disability. Chicago: U of Chicago Press, 2006. Print.

4. I acknowledge that it might be possible to see everyone as disabled and all of us probably have some disability, whether seen or "unseen" but at time of writing, I don't regard myself as having a disability.

5. See Note 1.

6. I proposed a series of five viewing positions as a means to determine the extent to which each either upholds or challenges conceptions of what dance is and what bodies are supposed to do in dance. I developed some of this thinking in a later publication. See: Whatley, Sarah. Moving Matters: Supporting Disabled Dance Students in HE. Coventry: CeMAP/Palatine, 2008. Print. Mitchell and Snyder consider critical modes of spectatorship in relation to disability documentary cinema, identifying some significant viewing relationships, but similarly state that they do not intend to imply that these are the only viewing positions available (158).

7. Deleuze, Giles. Cinema 1: The Movement-Image. Trans. Hugh Tomlinson and Barbara Habberjam. London: Athlone Press, 1986. Print. Rushton, Richard. “Deleuzian Spectatorship." Screen 50.1 (2009): 45-53. Print.

8. Cinema 1, see above.

—. Cinema 2: The Time-Image. Trans. Hugh Tomlinson and Barbara Habberjam. London: Athlone Press, 1989. Print.

9. Companies describe themselves in various ways: disabled, integrated, inclusive etc. In the UK there are a range of companies that include physically and learning-disabled dancers, including CandoCo Dance Company, Blue Eyed Soul Dance Company, Magpie, Anjali Dance Company, and Amici Dance Theatre Company.

10. Campbell, Fiona. "Reconstructing the Image of the Disabled Performer." Animated Spring (2009): n. pag. Web. 17 Mar. 2010

11. "Screendance." South East Dance. South East Dance: National Agency for the South East of England, n.d. Web. 17 Mar. 2010.

12. Notable disabled dance makers and company directors include Celeste Dandeker (co-founder, CandoCo Dance) and Judith Smith (Axis Dance Company). In the UK, there are initiatives to provide development support for disabled choreographers and dance leaders (such as the Transformations artist development program led by Blue Eyed Soul Dance Company) but there remain few established disabled choreographers.

13. Jones, Lucy. "Re:Bound."You Tube, 29 Sep. 2008. Web. 17 Mar. 2010.

14. Long, Catherine. "N.Y./Region: 'Collision' of Dance and Disability." Gimp. You Tube, 18 Mar. 2009. Web. 17 Mar. 2010.

15. Kappenberg, Claudia. "Does Screendance Need to Look like Dance?"International Journal of Performance Arts and Digital Media 5.2,3 (2009): 89-106.

16. Newson, Lloyd. "DV8 Physical Theater - The Cost of Living."You Tube, 29 Jan. 2008. Web. 17 Mar. 2010.

17. Newson is an established dance and performance maker with a long track record in making work for his company, DV8 Physical Theatre, which he named to make clear the emphasis on theatre, subject matter, and its ability to deviate from conventional views of dance. The film was commissioned by Channel 4 Television in the UK and received numerous screendance and screen Festival awards. The Cost of Living marked Newson's debut as a film director (previous dance films were made in collaboration with film directors).

18. Toole is well known in British dance, having established himself through a lengthy career working with several leading companies and building a reputation around his own particular and idiosyncratic movement range. As with other disabled dancers, his decision to perform may be motivated by his desire to be recognized as fully human, to remedy the lack which he embodies.

19. Both Albright (2001) and Briginshaw (2001) discuss the signification of the wheelchair in staged dance performances. Briginshaw is one of a number of commentators writing about disability in relation to dance who looks to Bakhtin's theory of the grotesque to explore the relationship between disability and excess. Briginshaw, Valerie. Dance, Space and Subjectivity. New York: Palgrave, 2001.

20. Different modes of looking; peering, staring, leering, recur throughout the film to remind the viewer of his/her own different modes of looking at screendance.

21. Ferris, Jim. "Aesthetic Distance and the Fiction of Disability." Sandahl and Auslander, 56-68. Print.

22. The divertissement in ballet is a familiar convention for providing a break from the narrative, an interlude or diversion from the main plot line. 
23. StopGap. "Chris and Lucy."You Tube, 29 Mar. 2008. Web. 17 Mar. 2010.

24. Perring, Giles. "The Facilitation of Learning-Disabled Arts: A Cultural Perspective." Sandahl and Auslander, 175-189. Print.

25. Lucy integrates carrying her shoes into the dance, which suggests that they signify both difference and similarity (Lucy having shoes but wanting to remove them to have the same tactile connection with the sand as Chris). Chris wears/carries no shoes. This difference between Lucy and Chris is rather curious and might carry more weight than is intended.

26. Manderson, Lenore and Susan Peake. "Men in Motion: Disability and the Performance of Masculinity." Sandahl and Auslander, 230-242. Print.

27. Merleau-Ponty, Maurice. The Phenomenology of Perception. Trans. Colin Smith. New York: Humanities Press, 1962.

28. Kuppers, Petra. "Bodies, Hysteria, Pain: Staging the Invisible." Sandahl and Auslander, 147-162. Print. 